\title{
A profile of poisoning in pediatric population in rural hospital in Jammu
}

\author{
Niraj Kumar ${ }^{1}$, Shallini Gupta ${ }^{2 *}$, Sanjeev Sharma ${ }^{3}$, Vikram Gupta
}

\author{
${ }^{1}$ Department of Pediatrics, ${ }^{2}$ Department of Pharmacology, Government Medical College, Doda, Jammu and Kashmir, \\ India \\ ${ }^{3}$ Department of Surgery, ${ }^{4}$ Department of Paediatrics, Sub district Hospital Akhnoor, Jammu, Jammu and Kashmir, \\ India
}

Received: 28 June 2021

Revised: 10 August 2021

Accepted: 11 August 2021

*Correspondence:

Dr. Shallini Gupta,

Email: shallinirajkdr@gmail.com

Copyright: ( $)$ the author(s), publisher and licensee Medip Academy. This is an open-access article distributed under the terms of the Creative Commons Attribution Non-Commercial License, which permits unrestricted non-commercial use, distribution, and reproduction in any medium, provided the original work is properly cited.

\begin{abstract}
Background: Acute poisoning is one of the commonest Pediatric emergencies and an important cause of morbidity and mortality. This study is aimed at understanding the incidence, aetiology and manner of poisoning, outcome among children less than 18 years reporting to Pediatric department at sub district Hospital level in Jammu region.

Methods: All the children between one month and eighteen years of age reporting to the Pediatric Emergency of SDH Akhnoor, Jammu over a period of one year as a case of acute poisoning were included in the study. The information obtained from subjects/parents/guardians and examinations of subjects was recorded on a pretested proforma and analyzed.

Results: A total of 150 patients were admitted as a case of poisoning over a study period of one year. Male: Female ratio was 1.41:1. Total incidence rate was 2.94/100 0 population over a period of one year. Majority of the cases were accidental $(94.67 \%)$ while suicidal attempt cases were $5.33 \%$. Most the cases $(49.33 \%)$ were due to accidental ingestion of household products followed by drug ingestion $(21.33 \%)$, food poisoning $(14 \%)$ and then agricultural/industrial products $(8 \%)$. Maximum patients $(86.6 \%)$ recovered while $2 \%$ referred to higher centre and rest $11.3 \%$ either absconded or lost to follow up.

Conclusions: Acute poisoning in children is usually accidental with favourable outcome. Death can happen depending upon nature of poison and the stage at which the patient is brought to the hospital. Poisoning can be prevented by increasing public awareness, counselling and right guidance to the parents.
\end{abstract}

Keywords: Poisoning, Pediatric population, Kerosene and pesticides

\section{INTRODUCTION}

Poisoning is a major emergency and a big problem in all age groups throughout the world. The cause and poisoning kind varies in numerous components of the world and among the country conjointly relying upon factors such as education, demography, socioeconomic factors, customs and native belief. ${ }^{1}$ Poisoning is quite common in Pediatric age bracket in developing and developed countries. There's nearly $1-6 \%$ of bed occupancy of poisoning cases in India and out of that $3.9 \%$ obtaining admission in PICU. ${ }^{2}$

Poisoning in children commonly happen due to ingestion of non-consumable household items, drugs, pesticides, noxious plant items incidentally or intentioned. Items like lamp fuel, Phenyl, naphthalene balls are common family items. Drugs available at home like Paracetamol, alprazolam, phenytoin, anti-thyroid drugs, anti- 
hypertensives, anti-diabetic etc are commonly ingested by children. ${ }^{3}$

According to World Health Organization (WHO) and United Nations International Children's Emergency Fund (UNICEF) Poisoning in childhood is common since children are inquisitive and explore their world most commonly by mouthing. ${ }^{4}$ Little children are continuously at risk of coincidental harming. Purposefulness poisoning is for the most part seen in youngster. In spite of the fact that poisoning never accounted for a large number of deaths, the decline in the rate of mortality has not been as extreme as infectious diseases, consequently has expected more prominence now.,

Pattern of poisoning varies according to age, the nature and dose of the poison and type of exposure. Among the accidental poisoning, even though there is no significant decrease in the number, the pattern of poisoning has shown a change with new hazards constantly appearing due to introduction of newer drugs and chemicals for domestic use, farming. ${ }^{7}$

Further, introduction of new drugs and chemicals and industrial growth has widened the spectrum of toxic products to which children may get exposed. However, accidental poisoning is mainly due to household products, which may vary according to the socio-cultural background of the family. Therefore, periodic review of data on pediatric poisoning from various centers is essential for providing the ever-changing information. In view of paucity of reports from Jammu region, it was considered worthwhile to analyze the cases of poisoning from a rural hospital in Jammu region in order to ascertain the pattern of commonly encountered poisons and suggest control measures to minimize such catastrophes.

\section{METHODS}

Present study was conducted prospectively from November 2018 to October 2019 in Subdistrict hospital Akhnoor of Jammu region. All the children between one month and eighteen years of age reporting to the Pediatric Emergency as a case of poisoning were study participants.

\section{Inclusion criteria}

Definite history of poisoning by any substance through any route i.e oral, parenteral, inhalational, dermal and ocular. Signs and symptoms seen commonly with a particular poison but without a definite history of poisoning (i.e suspected poisoning). The study participants/parents/guardians were subjected to detailed questioning after explaining the purpose of study. Patient was subjected to complete physical examination. Diagnosis was made mainly from history. Necessary blood examination, chemical analysis, radiological tests, ECG and other relevant investigations were done as and when required.

\section{Exclusion criteria}

All the cases of animal bites and stings were excluded from this study.

Data regarding age, sex, type of residence, type and quantity of substance consumed, time of ingestion, nature of ingestion, time of symptom onset, time of presentation to hospital, symptoms and signs, investigations, diagnostic and therapeutic interventions, and outcome was noted on a predesigned proforma.

Ethical clearance was taken from institutional ethical committee, GMC Jammu.

\section{Statistical analysis}

All the data from the duly filled proforma was transferred to a Microsoft Excel spreadsheet. The data was analysed using Statistical package for social sciences (SPSS) 10. Whole of the data was analysed by percentage.

\section{RESULTS}

Present study included 150 patients who were admitted as a case of poisoning over a period of one year. The incidence rate was 2.94 per 1000 population over a period of one year. Males were $88(58.66 \%)$ and females were 62 $(41.33 \%)$. Maximum $130(86.6 \%)$ patients recovered whereas $3(2 \%)$ referred to tertiary care centre GMC Jammu, rest $17(11.33 \%)$ either absconded or lost to follow up. The age and sex distribution of cases is shown in (Table 1).

Table 1: Age and sex distribution of poisoning.

\begin{tabular}{|lllll|}
\hline Age & Males & Females & Total & $\%$ \\
\hline I moth-1 year & 10 & 6 & 16 & 10.66 \\
\hline$>\mathbf{1 - 5}$ years & 55 & 40 & 95 & 63.33 \\
\hline$>\mathbf{5 - 1 0}$ years & 15 & 10 & 25 & 16.66 \\
\hline$>\mathbf{1 0 - 1 5}$ years & 6 & 3 & 9 & 6 \\
\hline$>\mathbf{1 5 - 1 8 y e a r s}$ & 2 & 3 & 5 & 3.33 \\
\hline Total & 88 & 62 & 150 & 100 \\
\hline
\end{tabular}

A majority of the cases were accidental 142 (94.67\%). Suicidal attempts constituted $8(5.33 \%)$ cases (Figure 1$)$.

Table 2: Category of poison.

\begin{tabular}{|c|c|c|}
\hline Category of poison & $\begin{array}{l}\text { No. of } \\
\text { patients (n) }\end{array}$ & $\begin{array}{l}\% \text { of } \\
\text { patients }\end{array}$ \\
\hline Household products & 74 & 49.33 \\
\hline Drugs & 32 & 21.33 \\
\hline Food & 21 & 14 \\
\hline $\begin{array}{l}\text { Agricultural/industrial } \\
\text { products }\end{array}$ & 12 & 8 \\
\hline Plants & 2 & 1.33 \\
\hline Unknown & 9 & 6 \\
\hline
\end{tabular}




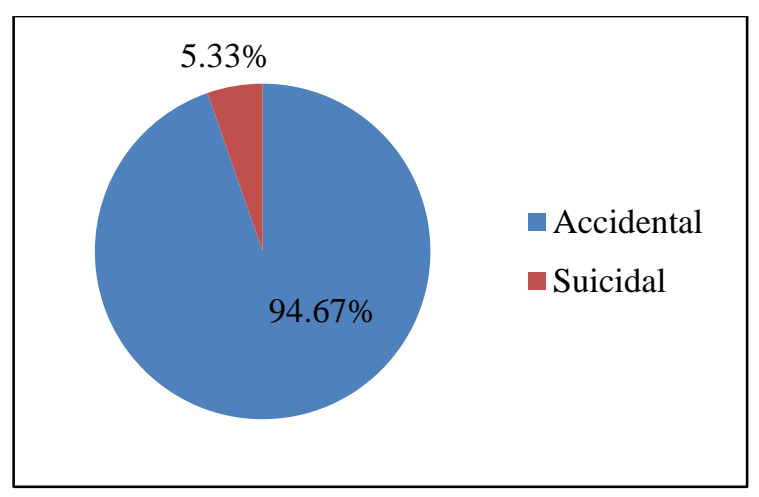

Figure 1: Mode of poisoning.

Majority (49.33\%) of poisoning cases were due to accidental ingestion of household products followed by drug ingestion (21.33\%), food poisoning (14\%) and agricultural/industrial products ingestion (8\%). Least cases were of plant poisoning $(1.33 \%)$. In $6 \%$ of cases the cause was unknown (Table 2).

Among household products maximum 30 (40.5\%) were of kerosene and pesticides poisoning followed by phenyl 17 $(22.97 \%)$, detergents and corrosives $8(10.8 \%)$ and thermometer mercury $6(8.10 \%)$. There were $2(2.7 \%)$ cases each of naphthalene, alcohol and battery water followed by $1(1.3 \%)$ case each of dettol, camphor, air freshener, boric acid, silica gel, ayurvedic massage oil and deodorant spray.

Drugs were the second most common cause of poisoning constituting $32(21.33 \%)$ of cases. This included anticonvolusant drugs like phenytoin, clonazepam, phenobarbitone, valproate about $9(28.12 \%)$ followed by sedatives and tranquillizers about $6(18.75 \%)$. Cold/cough syrups consisted of $4(12.5 \%)$ followed by antipyretics/analgesics $3(9.32 \%)$ and cyproheptadine 2 $(6.25 \%)$. There is 1 case $(3.125 \%)$ each of antiscabies lotion, lactocalamine lotion, loperamide, salbutamol, iron tablets, steroids, tincture iodine and ketoconazole shampoo.

Agricultural/industrial products were responsible for 12 (8\%) of cases out of which maximum $6(50 \%)$ were due to organophosphates followed by diesel $3(25 \%)$ and 1 $(8.3 \%)$ case each of aluminium phosphide, fertilizers and turpentine oil.

\section{DISCUSSION}

Poisoning in children is important cause of morbidity and mortality in developing countries like India. Our study aimed at describing magnitude of clinical problem and clinical profile of poisoning cases presented to Sub District Hospital, Akhnoor which is also the higher referral centre from adjoining CHCs and PHCs. With respect to sex preponderance, incidence was more common in males in less than 5 years of age group, whereas female predominance was seen in adolescent age group; with overall male predominance, similar incidence was seen in other studies as well. ${ }^{8-11}$. Predominance of males may be due to male preference in our society. Male children are brought to the hospital at the earliest even in doubtful cases.

In the present study maximum cases $(63.33 \%)$ were seen in the age group of more than one to 5 years which is similar to the findings of various other studies. ${ }^{12-14}$ High incidence of poisoning in this age group is probably due to their developmental stage and exploratory nature. By the age of 5 years incidence of accidental poisoning begin to decline due to the child selection for things that taste good for the purpose of ingestion.

Similar to the other observations made by any other studies maximum $(94.37 \%)$ were accidental. ${ }^{7,15} 5.33 \%$ cases were of suicidal attempt (all adolescents) in which cause was conflict with parents in 4 cases, poor performance in examinations 3 cases and failed love affair in one case.

In the present study the poisoning was mainly due to household products $(74 \%)$. Among household products kerosene was the most common factor $(40.5 \%)$ similar to other studies. ${ }^{16-18}$ This may be due to the reason that in rural areas still kerosene is commonly used for cooking purposes, kept in empty cold drink bottles is consumed accidentally by children.

In the present study, drugs constituted (32\%) 2nd most common cause of poisoning. Among drugs antiepileptics are the commonly used. One of the family members was on these drugs and kept them within reach of children.

Food poisoning occurred in $14 \%$ cases while due to agricultural products and plants occurred in $8 \%$ and $1.33 \%$ of cases. It is in agreement to few other studies. ${ }^{19,20}$ Majority of the patients $130(86.6 \%)$ patients recovered whereas $3(2 \%)$ were referred for PICU care at Government Medical College Jammu. Rest 17 (11.33\%) either absconded or lost to follow up.

\section{Limitation}

The current study has limitation of having small number of patients only emergency based and not OPD and single hospital based. Only data from hospital could be collected however there are many patients who go to local chemists and even quacks for treatment of mild cases, their data cannot be analysed.

\section{CONCLUSION}

Preventable accidental poisonings are still a significant cause of morbidity among younger children in developing countries, which can be reduced by keeping toxic agents out of reach of children, and parental education regarding poison proofing a child's environment. Suicidal poisoning has been shown to be more predominant in adolescents and teenagers hence need for a guidance and counselor at every 
school to help child deal with stressful situations, and to guide parents as well. In either case, the most important step is to bring child to the emergency room at the earliest this has been proven reduce the morbidity and mortality significantly.

Funding: No funding sources Conflict of interest: None declared

Ethical approval: The study was approved by the Institutional Ethics Committee

\section{REFERENCES}

1. Narayan Reddy KS. The essential of Forensic medicine \& Toxicology, 27th edition, Medical book company. 2008;95:440-56.

2. Aggarwal B, Rana SK, Chhavi N. Pattern of poisoning in children, an experience from a teaching hospital in northern India. JK Science. 2014;16(4):174178.

3. Lam LT. Childhood and adolescence poisoning in NSW, Australia: an analysis of age, sex, geographic, and poison types. Inj Prev. 2003;9:338-42.

4. WHO-UNICEF. Children and Poisoning: world report on child injury prevention. World Health Organisation. 2008.

5. Parikh CK. Toxicology. In: Parikh's text book of medical jurisprudence and toxicology. Parikh CK (ed). 5th Edn. Bombay. CBS publisher. 1990;660-90.

6. Reddy NKS. Toxicology. In: The synopsis of forensic medicine and toxicology. Narayan Reddy KS (ed). Medical book company. 2000;221-93.

7. Singh S, Singhi S, Sood NK, Kumar L, Walia BNS. Changing Pattern of childhood poisoning (19701989): Experience of a large North Indian hospital. Indian Paediatr. 1995;32:331-6.

8. Dutta AK, Seth A, Goyal PK. Poisoning in children. Indian Scenario. Indian J Pediatr. 1998;65:365-70.

9. Budhathoki S, Poudal P, Bhalla NK, Dutta AK, Shah GS, Bhutyal KK, et al. Clinical Profile and outcome of poisoning and intoxication in children. A hospital based study. Nepal Med Col J. 2009;11(3):170-5.
10. Bhat NK, Dhar M, Ahmad S, Chandr V. Profile of poisoning in children nd adolescents at North Indian tertiary care centre. JIACM. 2011;13:37-47.

11. Sharma J, Kaushal RK. Profile of poisoning in children. Pediatruc Oncall. 2014;11:40-2.

12. Kumar V. Acciental poisoning in South West Maharashtra. Indian Pediatrics. 1991;28:731-5.

13. Koushal U, Kuttait VS, Lodha R, Kabra SK. Profile of childhood poisoning at tertiary care centre in Norh India. Indian J Pediatrics.2008;75:791-4.

14. Gupta SK, Peshin SS, Srivastava A, Kaleekal T. A study of childhood poisoning at National Poisons Information Centre, All India Institute of Medical Sciences, New Delhi. J Occup Health. 2003;45:191-6.

15. Mehta A, Kasla RR, Bavdekar SB. Acute poisoning I children. J Indian Med Assoc. 1996; 94(6):219-20.

16. Khare Mm, Bhide MM, Ranade AA. poisoning in children-analysis of 250 cases. Journal of Post graduate Medicine. 1990;36(4):203-6.

17. Sharma U, Saxena S. Accidental poisoning in children in Jaipur(rajasthan). Indian Journal of Pediatrics. 1974;41:174-8.

18. Gupta S, Govil YC, Misra PK. Trends in poisoning in children. Experiences at large referral teaching hospital. Natl Med J India. 1998;11(4):166-8.

19. Krishankumar P, Geeta MG, Gopalan AV. Deliberate Self-Poisoning in Children. Indian Pediatr. 2005;42:582-6.

20. Basu K, Mondal RK, Banerjee DP. Epidemiological aspects of acute childhood poisoning among patients attending a hospital at Kolkata. Indian J Public Health. 2005;49:25-6.

Cite this article as: Kumar N, Gupta S, Sharma S, Gupta V. A profile of poisoning in pediatric population in rural hospital in Jammu. Int J Basic Clin Pharmacol 2021;10:1106-9. 